\section{Stoichiometry of An(III)-DMDOHEMA complexes formed during solvent extraction}

\author{
Patrik Weßling, ${ }^{* a, b}$ Michael Trumm, ${ }^{a}$ Andreas Geist ${ }^{a}$ and Petra \\ J. Panak ${ }^{\mathrm{a}, \mathrm{b}}$ \\ aKarlsruhe Institute of Technology (KIT), Institute for Nuclear Waste \\ Disposal (INE), P.O. Box 3640, 76021 Karlsruhe, Germany. \\ E-mail: patrik.wessling@kit.edu; \\ Tel: +49 (0)721 60824652
}

${ }^{b}$ Ruprecht-Karls-Universität Heidelberg, Institut für Physikalische Chemie,

Im Neuenheimer Feld 234, 69120 Heidelberg, Germany

$\mathrm{N}, \mathrm{N}^{\prime}$-dimethyl,N,N'-dioctylhexylethoxymalonamide (DMDOHEMA) is used to separate $A n(I I I)$ and $\operatorname{Ln}(I I I)$ from fission products in several liquid-liquid extraction processes that aim at recycling actinides. The stochiometry of the extracted complexes is important for a complete understanding of the processes. The presented work focuses on the complexation of $\mathrm{Cm}$ (III) with DMDOHEMA studied by TRLFS in mono- and biphasic (solvent extraction) systems. The formation of $[\mathrm{Cm}(\mathrm{DMDOHEMA})]^{3+}(\mathrm{n}=1-3)$ in 1-octanol containing $1.7 \mathrm{~mol} / \mathrm{L}$ of water with $\log \beta_{1}^{\prime}=2.6 \pm 0.3, \log \beta_{2}^{\prime}=4.0 \pm 0.5, \log \beta_{3}^{\prime}$ $=4.3 \pm 0.5$ was confirmed. In addition, fluorescence lifetime measurements indicated the formation of a 1:4 complex. Furthermore, solvent extraction experiments were performed, varying the proton and nitrate concentrations. TRLFS measurements of organic phases confirmed the existence of two species, $\left[\mathrm{Cm}(\mathrm{DMDOHEMA})_{3}\left(\mathrm{NO}_{3}\right)\left(\mathrm{H}_{2} \mathrm{O}\right)_{1-2}\right]^{2+}$ (dominant at high proton and nitrate concentrations) and $\left[\mathrm{Cm}(\mathrm{DMDOHEMA})_{4}\left(\mathrm{H}_{2} \mathrm{O}\right)\right]^{3+}$ (dominant at low proton and nitrate concentrations). To support the proposed stoichiometries, vibronic side-band spectroscopy (VSBS) was employed, allowing the observation of vibrations of functional groups coordinated to the probed metal ion. Clear differences between the vibronic side bands of the 1:3 and $1: 4$ complex in the range of $900-1300 \mathrm{~cm}^{-1}$ were observed. Vibrational spectra calculated by DFT complimented the experimental data and confirmed the proposed stoichiometries. They revealed a monodentate coordination mode of the nitrate and two water molecules in the 1:3 complex.

\section{Introduction}

Malonamides (Scheme 1) are bidentate chelating ligands that coordinate metal ions via the amide oxygen atoms. ${ }^{1}$ Their complexing properties depend on the substitution of the moieties on the amide groups $\left(R^{1}-R^{2}\right)$ and the methylene unit $\left(R^{3}-R^{4}\right) .^{2,3}$ Substitution of $R^{1}$ and $R^{2}$ with long alkyl moieties diminishes the complexing properties due to steric hindrance but improves solubility in organic solvents. ${ }^{4,5}$ Substitution of $R^{3}$ and $\mathrm{R}^{4}$ with alkyl chains also improves the solubility in organic solvents. Yet, metal ion coordination becomes more difficult for monosubstituted malonamides and can even be impossible for disubstituted malonamides. ${ }^{2}$

Malonamides have been developed as extracting agents for several solvent extraction processes for separating actinides from spent nuclear fuels. ${ }^{6}$ They extract tri-, tetra- and hexavalent actinides, lanthanides and some transition metals (e.g. $\mathrm{Zr}, \mathrm{Pd}, \mathrm{Mo}$ ) from acidic, nitrate containing solutions. ${ }^{7-9}$
$\mathrm{N}, \mathrm{N}$ '-dimethyl,N,N'-dioctylhexylethoxymalonamide (DMDOHEMA) is highly soluble in kerosene and 1-octanol due to the octyl and hexylethoxy moieties. ${ }^{10}$ Additionally, the methyl moieties on the amides reduces steric hindrance so that metal-ion complexation and extraction are ensured. The ether oxygen does not coordinate to the metal ion. ${ }^{11,12}$

DMDOHEMA has been chosen as an extracting agent for several solvent extraction processes for separating actinides from spent nuclear fuels. Among these processes are the DIAMEX (DIAMide EXtraction) ${ }^{13}$, EXAm (EXtraction of Americium) ${ }^{14}$ and GANEX (Grouped ActiNide Extraction) ${ }^{15}, 16$ processes.

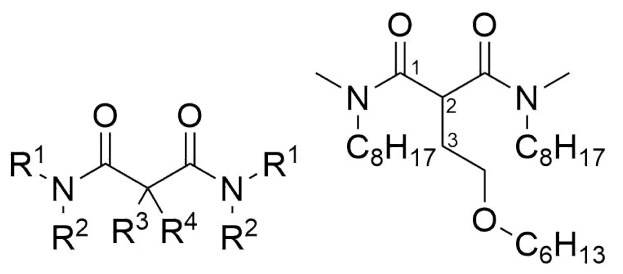

Scheme 1 General framework of malonamides (left) and molecular structure of DMDOHEMA (right).

Lipophilic malonamides extract nitric acid and water, forming the following adducts $\left(\mathrm{L}=\right.$ malonamide): $\left(\mathrm{HNO}_{3}\right)_{\mathrm{x}} \cdot \mathrm{L}(\mathrm{x}=$ $1,2),\left(\mathrm{HNO}_{3}\right) \cdot \mathrm{L}_{2}$ and $\left(\mathrm{H}_{2} \mathrm{O}\right) \cdot \mathrm{L} \cdot{ }^{17-20}$

Furthermore, malonamides are reported to extract actinide(III) and lanthanide(III) nitrates from nitrate solutions as $\mathrm{M}\left(\mathrm{NO}_{3}\right)_{3} \cdot \mathrm{L}_{x}(x=2-4)$ complexes. ${ }^{2,5}$ Extraction from nitric acid involves the formation of several additional complexes, $\mathrm{M}\left(\mathrm{NO}_{3}\right)_{3} \cdot\left(\mathrm{HNO}_{3}\right)_{x} \cdot \mathrm{L}_{y}(x=1-2 \text { and } y=2-4)^{4,18}$

The extraction of Am(III) from 0.1-7 mol/ $\mathrm{LNO}_{3}$ into 0.5$1.0 \mathrm{~mol} / \mathrm{L}$ DMDOHEMA dissolved in kerosene is reported to proceed through the formation of $\mathrm{Am}\left(\mathrm{NO}_{3}\right)_{3} \cdot \mathrm{L}_{4}$, $\mathrm{Am}\left(\mathrm{NO}_{3}\right)_{3} \cdot \mathrm{HNO}_{3} \cdot \mathrm{L}_{3}$ and $\mathrm{Am}\left(\mathrm{NO}_{3}\right)_{3} \cdot\left(\mathrm{HNO}_{3}\right)_{2} \cdot \mathrm{L}_{2} \cdot{ }^{20}$ However, the formation of the aforementioned complexes was derived from slope analysis of solvent extraction experiments only; no further evidence for their presence was sought.

Time-resolved laser fluorescence spectroscopy (TRLFS) is a sensitive and non-invasive analytical method to study the inner coordination sphere of fluorescent metal ions. TRLFS has become a valuable analytical method for speciation in solution for both lanthanides and actinides $(\mathrm{Cm}$ (III) being a representative for trivalent actinides due to its spectroscopic properties). Information about the number and type of ligands as well as the complex geometry is obtained by spectroscopic parameters such as shape, position, intensity of the emission bands and lifetime of the fluorescence emission. ${ }^{21,} 22$

We present a TRLFS study on the complexation of $\mathrm{Cm}$ (III) with DMDOHEMA in mono- and biphasic (i.e. solvent extraction) systems, elucidating the stoichiometry of the complexes formed during extraction from acidic nitrate solutions. Furthermore, we apply vibronic side-band spectroscopy (VSBS) to support our findings. VSBS is a technique to study the near coordination environment of luminescent metal ions. ${ }^{23-28}$ Density functional theory (DFT) is employed on proposed complex geometries in order to complement experimental results and highlight the origin of changes in the vibrational manifolds. 


\section{Experimental section}

\section{Chemicals}

All chemicals were used as purchased or provided without further purification. DMDOHEMA was provided by Dr. Rikard Malmbeck (European Joint Research Centre). Deuterated nitric acid was purchased from Deutero $\mathrm{GmbH}$. All other chemicals were obtained from Sigma Aldrich.

\section{Preparation of monophasic samples}

For monophasic experiments $4.7 \mu \mathrm{L}$ of a $\mathrm{Cm}$ (III) stock solution were dissolved in $995.3 \mu \mathrm{L}$ of solvent, resulting in an initial $\mathrm{Cm}$ (III) concentration of $1 \times 10^{-7} \mathrm{~mol} / \mathrm{L}$.

To study the influence of the water concentration in 1-octanol on the emission spectra of $\mathrm{Cm}$ (III) aliquots of ultrapure water were added in $1.5 \mu \mathrm{L}$ steps until saturation. The water concentration in water-saturated 1-octanol is approximately $2 \mathrm{~mol} / \mathrm{L}^{29}, 30$. To avoid the formation of an aqueous phase when studying the complexation of $\mathrm{Cm}$ (III) with DMDOHEMA 1-octanol with $1.7 \mathrm{~mol} / \mathrm{L}$ water was used as solvent.

A DMDOHEMA stock solution was prepared by dissolving $1.524 \mathrm{~g}$ of DMDOHEMA in 1-octanol containing $1.7 \mathrm{~mol} / \mathrm{L}$ water to a total volume of $2 \mathrm{~mL}$, resulting in a DMDOHEMA concentration of $1.58 \mathrm{~mol} / \mathrm{L}$. This stock solution was diluted to $0.1 \mathrm{~mol} / \mathrm{L}$ and $0.01 \mathrm{~mol} / \mathrm{L}$ DMDOHEMA by adding 1 -octanol containing $1.7 \mathrm{~mol} / \mathrm{L}$ water.

\section{Solvent extraction}

To compare the species formed in mono- and biphasic experiments, extraction experiments with $\mathrm{Cm}$ (III) and DMDOHEMA were performed as a function of the proton and nitrate concentrations.

Organic phase was $0.4 \mathrm{~mol} / \mathrm{L}$ DMDOHEMA in kerosene. To study the influence of the proton concentration, aqueous phases were $1 \times 10^{-3} \mathrm{~mol} / \mathrm{L}-6.0 \mathrm{~mol} / \mathrm{L}$ nitric acid with a constant nitrate concentration of $6.0 \mathrm{~mol} / \mathrm{L}$. The influence of the nitrate concentration was studied using aqueous phases with nitrate concentrations of $1.0 \mathrm{~mol} / \mathrm{L}-6.0 \mathrm{~mol} / \mathrm{L}$ and a constant proton concentration of $0.4 \mathrm{~mol} / \mathrm{L}$.

$500 \mu \mathrm{L}$ of both aqueous and organic phase were shaken for $20 \mathrm{~min}$ at $298 \mathrm{~K}$ in a $2 \mathrm{~mL}$ screw-cap vial on an orbital shaker (2500 rpm). Phases were separated by centrifugation (6000 rpm) and $300 \mu \mathrm{L}$ aliquots of each phase were investigated by TRLFS.

\section{TRLFS}

All experiments were performed at $298 \mathrm{~K}$ with a Nd:YAG (Surelite II laser, Continuum) pumped dye laser system (NarrowScan D-R; Radiant Dyes Laser Accessories GmbH). A wavelength of $396.6 \mathrm{~nm}$ was chosen to excite $\mathrm{Cm}$ (III). A spectrograph (Shamrock 303i, ANDOR) with 300, 1199 and 2400 lines per $\mathrm{mm}$ gratings was used for spectral decomposition. The fluorescence emission was detected by an ICCD camera (iStar Gen III, ANDOR) after a delay time of $1 \mu \mathrm{s}$ using a gate width of $1 \mathrm{~ms}$ to discriminate short-lived, organic fluorescence and light scattering.

\section{VSBS}

Samples for VSBS were prepared by extraction (see Solvent extraction). Organic phases consisted of $0.4 \mathrm{~mol} / \mathrm{L}$ DMDOHEMA in kerosene. Aqueous phases were $6.0 \mathrm{~mol} / \mathrm{L} \quad \mathrm{NH}_{4} \mathrm{NO}_{3}$ or $10^{-3} \mathrm{~mol} / \mathrm{L} \mathrm{HNO}_{3}$ in $6.0 \mathrm{~mol} / \mathrm{L} \mathrm{NH}_{4} \mathrm{NO}_{3}$. Deuterated aqueous phases were prepared using $\mathrm{NaNO}_{3}, \mathrm{D}_{2} \mathrm{O}$ and $\mathrm{DNO}_{3}$. For vibronic side-band detection $\mathrm{Cm}$ (III) emission spectra were recorded in a wavelength range of $620 \mathrm{~nm}-800 \mathrm{~nm}$ with a 1199 lines per $\mathrm{mm}$ grating. The aforementioned wavelength range was scanned by gradually shifting the central wavelength of the grating in $10 \mathrm{~nm}$ steps as the detection width of the grating is limited to $40 \mathrm{~nm}$. The depicted vibronic side-band spectra resemble sequences of several $\mathrm{Cm}$ (III) emission spectra.

\section{Theoretical model}

DFT computations on the BP8631,32/def2-TZVP33 level were performed for various $1: 3$ and $1: 4 \mathrm{Cm}$ (III)-DMDOHEMA complexes. The $\mathrm{Cm}$ (III) ion was described by a ECP60MWB ${ }^{34}$ small-core pseudo potential. Vibrational modes were computed to verify true minima of the optimised structures using the TURBOMOLE 35 program package. For comparison with the VSBS data all vibrational intensities were scaled by $r^{-6}$ for each atom depending on its contribution to the mode, with $r$ being the atom distance to the central $\mathrm{Cm}$ (III) ion. Resulting vibrational spectra were obtained using Gaussian line broadening on the determined frequencies and intensities.

\section{Results and Discussion}

\section{$\mathrm{Cm}$ (III) emission spectra in 1-octanol}

Figure 1 shows the evolution of the $\mathrm{Cm}$ (III) fluorescence spectra $\left({ }^{6} D_{7 / 2} \rightarrow{ }^{8} S_{7 / 2}\right)$ with increasing water concentration in 1-octanol. The fluorescence spectra of $\mathrm{Cm}$ (III) in 1-octanol show a strong dependency on the water content.

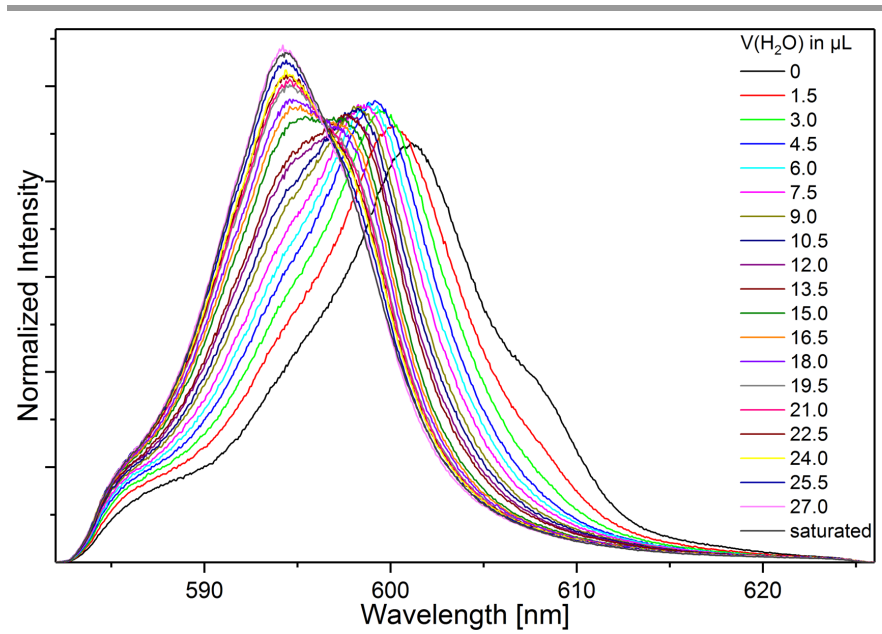

Fig. 1 Normalized fluorescence spectra of $\mathrm{Cm}$ (III) in 1-octanol in dependence of the added amount of water $\left(\mathrm{c}(\mathrm{Cm}(\mathrm{III}))_{\text {ini }}=1 \times 10^{-7} \mathrm{M}\right)$.

$\mathrm{Cm}$ (III) in 1-octanol (as received) has an emission band at $601.2 \mathrm{~nm}$ with a shoulder on the bathochromic side at $607.2 \mathrm{~nm}$. Sequential addition of water results in a gradual hypsochromic shift of the $\mathrm{Cm}$ (III) emission band. The shoulder on the bathochromic side of the spectrum disappears. After 
adding $27 \mu \mathrm{L}$ of water no further changes of the $\mathrm{Cm}$ (III) emission band are observed. The emission band is located at $594.3 \mathrm{~nm}$ with a shoulder at $597.3 \mathrm{~nm}$. The emission spectrum is identical to the spectrum of $\mathrm{Cm}$ (III) dissolved in water-saturated 1-octanol.

These results indicate that the solvation of $\mathrm{Cm}$ (III) changes with increasing water concentration in 1-octanol. In watersaturated 1-octanol $\mathrm{Cm}$ (III) is almost exclusively coordinated by water molecules. The $\mathrm{Cm}$ (III) emission band is close to that of the $\mathrm{Cm}$ (III) aqua ion $\left(\lambda_{\max }=593.8 \mathrm{~nm}\right)^{36-38}$. Decreasing the water concentration in 1-octanol results in a pronounced coordination of 1-octanol molecules, causing a bathochromic shift. These findings are supported by $\mathrm{Cm}$ (III) fluorescence lifetime measurements. The fluorescence lifetime of $\mathrm{Cm}$ (III) in 1-octanol (without addition of water) is $\tau=(108 \pm 9) \mu \mathrm{s}$, whereas in watersaturated 1-octanol a lifetime of $\tau=(77 \pm 7) \mu$ s is observed. As the fluorescence of $\mathrm{Cm}$ (III) is mainly quenched by water molecules longer fluorescence lifetimes correlate with fewer coordinated water molecules. ${ }^{37}$

Similar trends are also observed for $\mathrm{Cm}$ (III) solvent spectra in binary, miscible solvent mixtures $\left(\mathrm{H}_{2} \mathrm{O}+\mathrm{MeOH}, \mathrm{PrOH}^{\mathrm{t}}{ }^{\mathrm{BuOH}}\right.$, $\mathrm{Me}_{2} \mathrm{CO}$, DMSO or $\mathrm{CH}_{3} \mathrm{CN}$ ) in which $\mathrm{Cm}$ (III) is mainly coordinated by water. Bathochromic shifts of the $\mathrm{Cm}$ (III) emission band and longer fluorescence lifetimes due to replacement of water by other solvent molecules are observed solely at very low water concentrations. ${ }^{39,} 40$

\section{Complexation of $\mathrm{Cm}$ (III) with DMDOHEMA}

Figure 2 shows the normalized fluorescence spectra of $\mathrm{Cm}(\mathrm{III})$ in 1-octanol containing $1.7 \mathrm{~mol} / \mathrm{L}$ water in dependence of the DMDOHEMA concentration. In absence of DMDOHEMA an emission band at $594.3 \mathrm{~nm}$ with a shoulder at $597.5 \mathrm{~nm}$ is observed. The addition of DMDOHEMA leads to a bathochromic shift that becomes more pronounced for higher DMDOHEMA concentrations. At the highest ligand concentration $(0.829 \mathrm{~mol} / \mathrm{L})$ an emission band at $602.7 \mathrm{~nm}$ is detected.

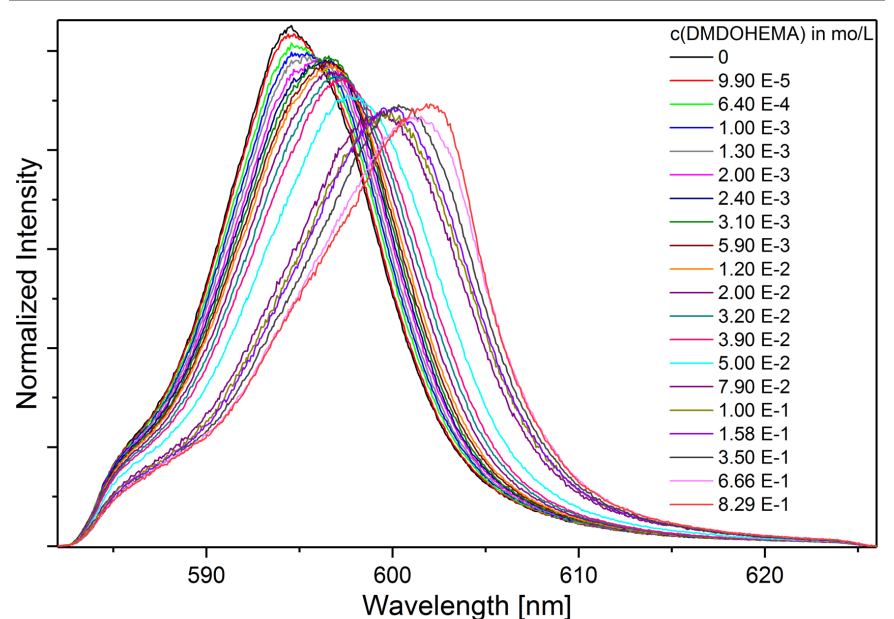

Fig. 2 Normalized fluorescence spectra of $\mathrm{Cm}$ (III) in 1-octanol containing $1.7 \mathrm{~mol} / \mathrm{L}$ water at increasing DMDOHEMA concentrations $\left(\mathrm{c}(\mathrm{Cm}(\mathrm{III}))_{\text {ini }}=1 \times 10^{-7} \mathrm{~mol} / \mathrm{L}\right)$.

By subtracting the emission spectrum of the $\mathrm{Cm}$ (III) solvent species from the spectra at $1.0 \times 10^{-3} \mathrm{~mol} / \mathrm{L}, 1.2 \times 10^{-2} \mathrm{~mol} / \mathrm{L}$ and $1.0 \times 10^{-1} \mathrm{~mol} / \mathrm{L}$ DMDOHEMA, single component spectra for the $\left[\mathrm{Cm}(\text { DMDOHEMA })_{n}\right]^{3+}$ complexes $(n=1-3)$ are obtained
(Figure 3) with emission bands at $596.5 \mathrm{~nm}, 598.5 \mathrm{~nm}$ and $601.9 \mathrm{~nm}$, respectively. The decreasing signal to noise ratio of the single component spectra of the $1: 2$ and $1: 3$ complex is due to their small contribution to the total peak area in the deconvoluted spectra. The bathochromic shifts of the single component spectra relative to the solvent spectrum are due to the increased ligand field splitting and support the gradual complexation of $\mathrm{Cm}$ (III) with DMDOHEMA. The shifts of the emission bands are small compared to shifts observed for other oxygen based extracting agents such as TODGA. ${ }^{41}$

The relative fractions of the single component spectra in the experimental spectra are obtained by peak deconvolution. To determine species concentrations the relative fractions are corrected by fluorescence intensity (FI) factors. FI factors denote the fluorescence intensity of single component spectra relative to the intensity of the solvent spectrum. The $\mathrm{FI}$ values are $\mathrm{Fl}_{1}=1.4 \pm 0.1, \mathrm{Fl}_{2}=1.2 \pm 0.3$ and $\mathrm{Fl}_{3}=3.9 \pm 0.8$.

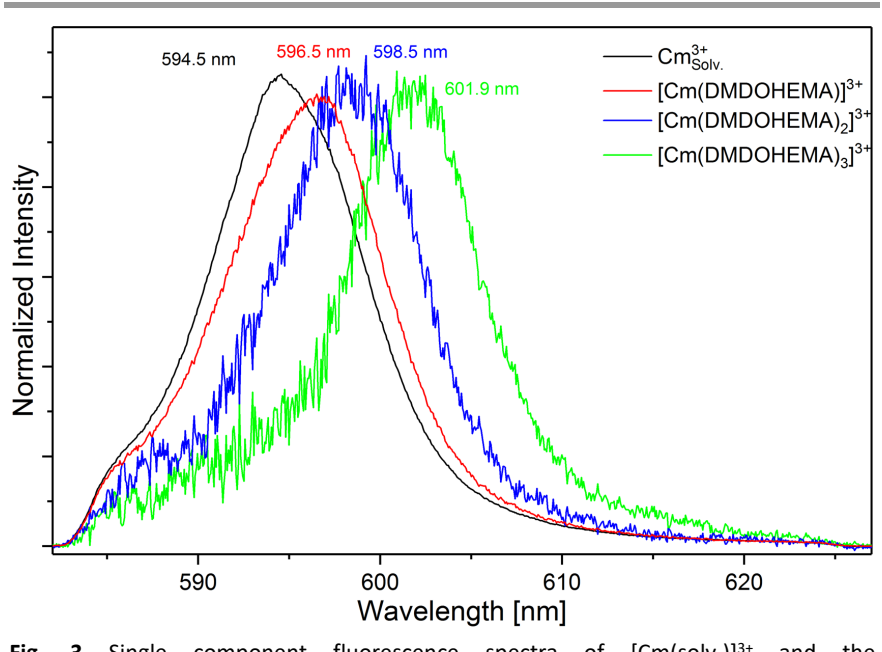

Fig. 3 Single component fluorescence spectra of $[\mathrm{Cm}(\text { solv. })]^{3+}$ and the $\left[\mathrm{Cm}(\text { DMDOHEMA })_{n}\right]^{3+}$ complexes $(n=1-3)$ in 1 -octanol containing $1.7 \mathrm{~mol} / \mathrm{L}$ water.

Figure 4 shows the resulting speciation diagram. Formation of the $1: 1$ complex starts at $1 \times 10^{-4} \mathrm{~mol} / \mathrm{L}$ DMDOHEMA and has a maximum at approximately $1 \times 10^{-2} \mathrm{~mol} / \mathrm{L}$ DMDOHEMA with a fraction of almost $70 \%$. Formation of the $1: 2$ complex starts at $1 \times 10^{-3} \mathrm{~mol} / \mathrm{L}$ DMDOHEMA and has a maximum share of $65 \%$ at approximately $0.1 \mathrm{~mol} / \mathrm{L}$ DMDOHEMA. Formation of the 1:3 complex occurs at $0.05 \mathrm{~mol} / \mathrm{L}$ DMDOHEMA. Due to the small fraction relative to the total peak area no single component spectrum of the 1:4 complex is obtained. Nevertheless, lifetime measurements indicate the existence of a 1:4 complex as they display lifetime components exceeding the fluorescence lifetime expected for a 1:3 complex $\left(\tau_{1: 3 \text { complex }} \approx 170 \mu \mathrm{s}\right)$. 


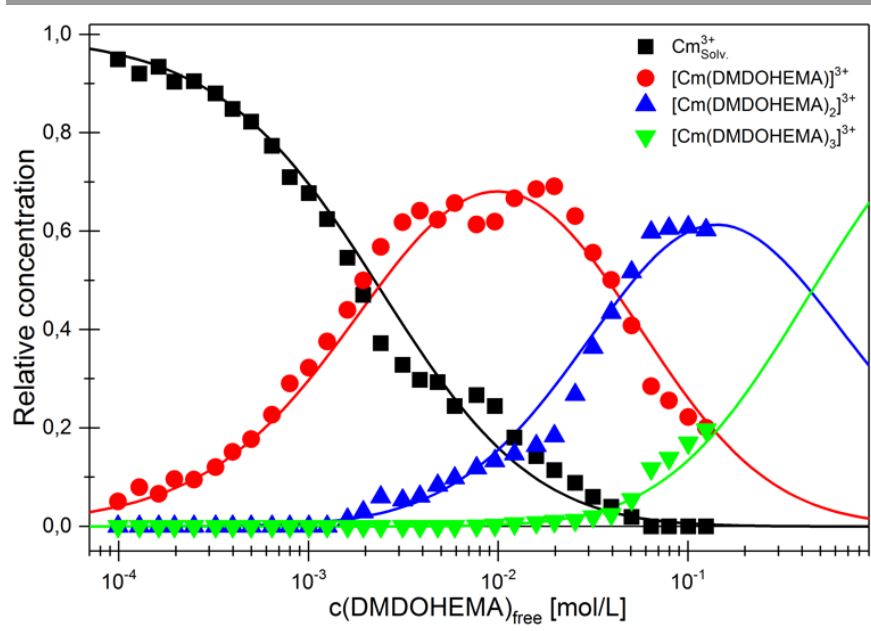

Fig. 4 Relative concentration of $[\mathrm{Cm}(\text { Solv. })]^{3+}$ and the $\left[\mathrm{Cm}(\mathrm{DMDOHEMA})_{\mathrm{n}}\right]^{3+}$ complexes $(n=1-3)$ as a function of the free DMDOHEMA concentration in 1-octanol containing $1.7 \mathrm{~mol} / \mathrm{L}$ water. Dots, experimental data. Lines, calculated with $\log \beta_{1}^{\prime}=2.6$, $\log \beta_{2}{ }_{2}=4.0$ and $\log \beta_{3}^{\prime}=4.3$.

To verify the stoichiometry assigned to the single component spectra, slope analyses according to equation (1) are performed.

$$
\begin{gathered}
\left(\mathrm{ML}_{n-1}\right)^{3+}+L \rightleftharpoons\left(\mathrm{ML}_{n}\right)^{3+} \\
\log \frac{c\left(\left(M L_{n}\right)^{3+}\right)}{c\left(\left(M L_{n-1}\right)^{3+}\right)}=\log c(L)+\log K_{n}^{\prime}
\end{gathered}
$$

Equation (1) describes a linear correlation between the logarithms of the free ligand concentration and the concentration ratio of $\mathrm{c}\left(\left(\mathrm{ML}_{n}\right)^{3+}\right) / \mathrm{c}\left(\left(\mathrm{ML}_{\mathrm{n}-1}\right)^{3+}\right.$. The slopes shown in Figure 5 confirm the stepwise addition of DMDOHEMA to form the 1:1,1:2 and 1:3 complexes.

Conditional stability constants are calculated according to equation (2).

$$
\beta_{n}^{\prime}=\frac{c\left(\left(M L_{n}\right)^{3+}\right)}{\mathrm{c}\left(\mathrm{M}^{3+}\right)(c(L))^{n}}
$$

The resulting conditional stability constants are $\log \beta_{1}{ }_{1}=2.6 \pm$ $0.3, \log \beta_{2}^{\prime}=4.0 \pm 0.5$ and $\log \beta_{3}^{\prime}=4.3 \pm 0.5$.

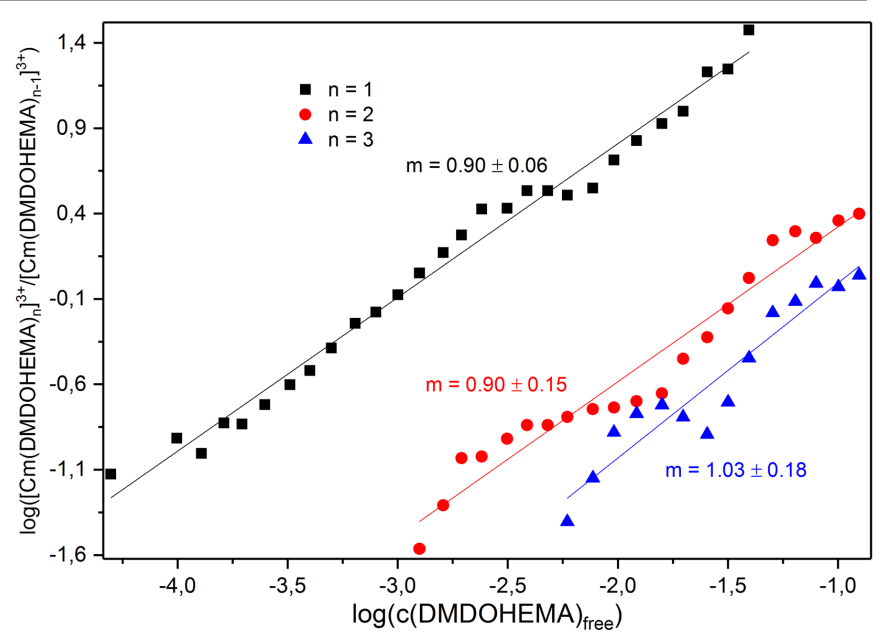

Fig. 5 Double logarithmic plot of the concentration ratio of $\left[\mathrm{Cm}(\mathrm{DMDOHEMA})_{n}\right]^{3+} /$ $\left[\mathrm{Cm}(\mathrm{DMDOHEMA})_{\mathrm{n}-1}\right]^{3+}$ as a function of the free DMDOHEMA concentration.

\section{Solvent extraction experiments}

To determine the stoichiometry of the complexes formed upon extraction of actinides(III) from acidic nitrate solutions into DMDOHEMA dissolved in kerosene, solvent extraction experiments are performed. The influence of proton and nitrate concentrations on the formed complexes in the organic and aqueous phases are investigated by TRLFS. In the following, only the $\mathrm{Cm}$ (III) emission spectra of the organic phases are shown. Emission spectra of the aqueous phases and data of lifetime measurements are given in the supplementary information (Figures S 2-4 and Tables S 1-2).

Influence of proton concentration. Extraction experiments are performed with proton concentrations in the range of $1 \mathrm{x}$ $10^{-3} \mathrm{~mol} / \mathrm{L}-6.0 \mathrm{~mol} / \mathrm{L}$ at constant nitrate and DMDOHEMA concentrations. The organic phase $\mathrm{Cm}$ (III) emission spectra are shown in Figure 6.

Depending on the proton concentration, two different species are observed. Species I, exhibiting an emission band at $601.3 \mathrm{~nm}$ with a hot band at $595.6 \mathrm{~nm}$, is present at high proton concentrations. Species II shows an emission band at $604.2 \mathrm{~nm}$ with a hot band at $596.8 \mathrm{~nm}$. It is observed at low proton concentrations. An isosbestic point is found at $602.4 \mathrm{~nm}$, indicating the direct transformation of species I into species II with decreasing proton concentration.

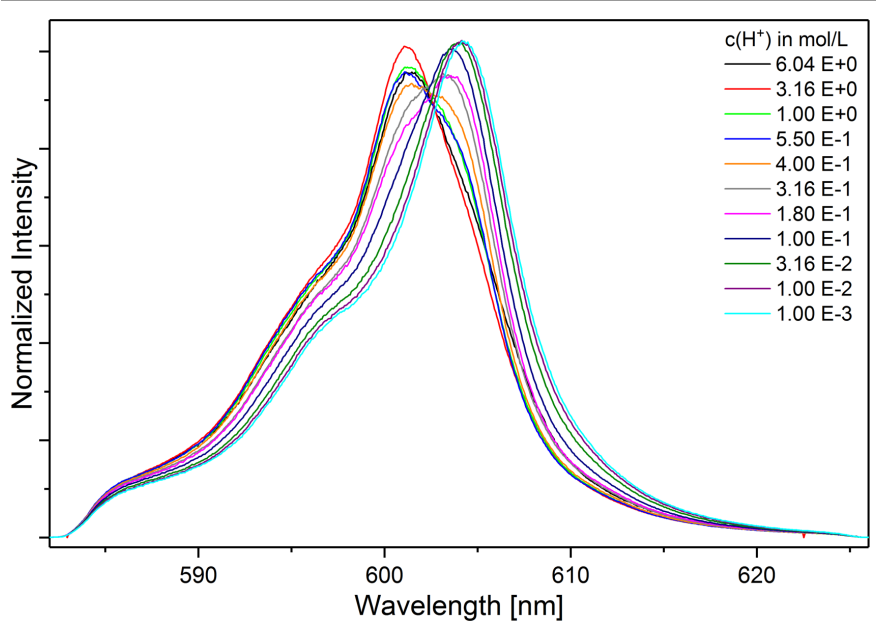

Fig. 6 Normalized fluorescence spectra of $\mathrm{Cm}$ (III) in the organic phases from solvent extraction experiments at varied aqueous phase proton concentration. $\mathrm{c}(\mathrm{Cm}(\mathrm{III}))_{\text {ini }}=$ $\left.1 \times 10^{-7} \mathrm{~mol} / \mathrm{L}, \mathrm{c}\left(\mathrm{NO}_{3}{ }^{-}\right)_{\text {ini }}=6.0 \mathrm{~mol} / \mathrm{L}\right), \mathrm{c}(\text { DMDOHEMA })_{\text {ini }}=0.4 \mathrm{~mol} / \mathrm{L}$.

Influence of nitrate concentration. The influence of the nitrate concentration is studied at constant proton $(1 \mathrm{~mol} / \mathrm{L})$ and DMDOHEMA (0.4 mol/L) concentrations. The $\mathrm{Cm}(\mathrm{III})$ emission spectra are shown in Figure 7. Again, two species with the same emission maxima are observed (cf. Figure 6). Species I $(601.3 \mathrm{~nm})$ is dominant at high nitrate concentrations whereas species II (604.2 $\mathrm{nm}$ ) is dominant at low nitrate concentrations. The influence of the nitrate concentration on the position of the emission band of $\mathrm{Cm}$ (III) is weaker than that of the proton concentration. The most pronounced change of the emission spectra is found between nitrate concentrations of $2 \mathrm{~mol} / \mathrm{L}$ and $5 \mathrm{~mol} / \mathrm{L}$. No substantial change is observed between $1 \mathrm{~mol} / \mathrm{L}$ and $2 \mathrm{~mol} / \mathrm{L}$ nitrate and between $5 \mathrm{~mol} / \mathrm{L}$ and $6 \mathrm{~mol} / \mathrm{L}$ nitrate. 


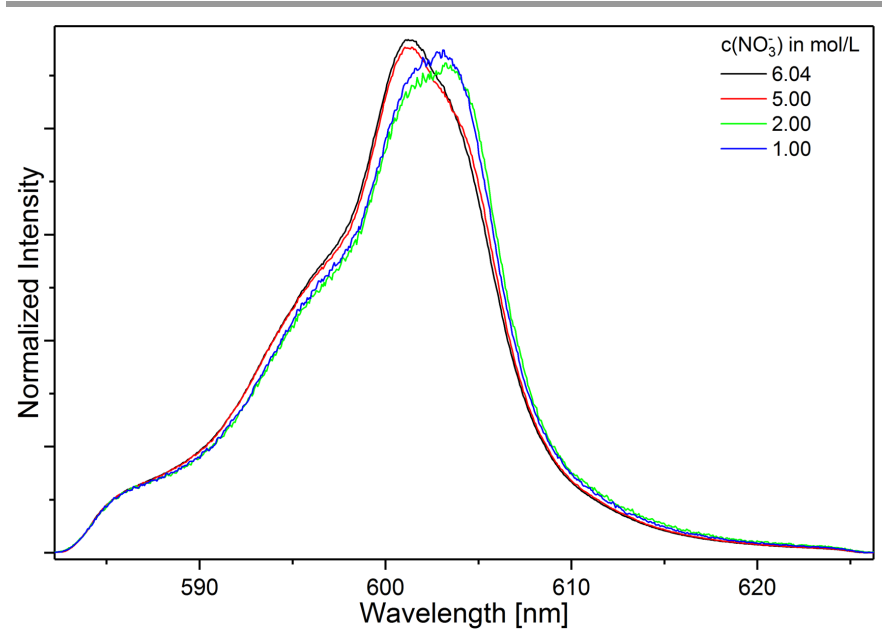

Fig. 7 Normalized fluorescence spectra of $\mathrm{Cm}$ (III) in the organic phases from solvent extraction experiments at varied nitrate concentration. $\mathrm{c}(\mathrm{Cm}(\mathrm{III}))_{\text {ini }}=1 \times 10^{-7} \mathrm{~mol} / \mathrm{L}$, $\left.\mathrm{c}\left(\mathrm{H}^{+}\right)_{\text {ini }}=1 \mathrm{~mol} / \mathrm{L}\right), \mathrm{c}(\mathrm{DMDOHEMA})_{\text {ini }}=0.4 \mathrm{~mol} / \mathrm{L}$

Interpretation of the solvent extraction experiments. Depending on the experimental conditions (i. e. proton and nitrate concentrations), two Cm(III)-DMDOHEMA complexes are identified.

- Species I, having an emission maximum at $601.3 \mathrm{~nm}$, prevails at conditions of high proton and nitrate concentrations:

- Species II, having an emission maximum at $604.2 \mathrm{~nm}$, prevails at conditions of lower proton and nitrate concentrations.

The number of DMDOHEMA molecules in species I is determined by comparison of the single component spectra of the $\left[\mathrm{Cm}(\mathrm{DMDOHEMA})_{n}\right]^{3+}(\mathrm{n}=1-3)$ complexes in 1-octanol (Figure 3) with the spectra of the solvent extraction experiments. Figure 8 shows the spectrum of the 1:3 complex from monophasic experiments and the spectrum of species $I$. The position of the emission bands are in excellent agreement, confirming species I to be a 1:3 complex. Six coordination sites are occupied by three bidentate DMDOHEMA molecules. This leaves three sites of the typically ninefold-coordinated $\mathrm{Cm}$ (III) ion ${ }^{36}$ vacant for further ligands.

The slight deviations between the spectra of the mono- and biphasic systems arise from those three positions. In the monophasic system, only 1-octanol and water are possible ligands besides DMDOHEMA. In the biphasic system nitrate and water have to be considered.

The number of water molecules present in the first coordination sphere is estimated from fluorescence lifetime measurements according to the equation of Kimura et. $a^{37}$. For conditions with prevailing presence of species I, the calculated number of inner sphere water molecules is in the range of 1.41.6 (see supplementary information Tables S1-S2). This implies species I being either $\left[\mathrm{Cm}(\mathrm{DMDOHEMA})_{3}\left(\mathrm{NO}_{3}\right)\left(\mathrm{H}_{2} \mathrm{O}\right)\right]^{2+}$ with a bidentate nitrate anion or $\left[\mathrm{Cm}(\mathrm{DMDOHEMA})_{3}\left(\mathrm{NO}_{3}\right)\left(\mathrm{H}_{2} \mathrm{O}\right)_{2}\right]^{2+}$ with a monodentate nitrate anion.

Species II is shifted bathochromically with respect to species I. The stronger ligand field splitting of species II is explained by coordination of a further DMDOHEMA molecule. Slightly longer fluorescence lifetimes are observed for conditions at which species II prevails. The calculated number of water molecules is 1.2-1.4, confirming species II to be $\left[\mathrm{Cm}(\mathrm{DMDOHEMA})_{4}\left(\mathrm{H}_{2} \mathrm{O}\right)\right]^{3+}$.

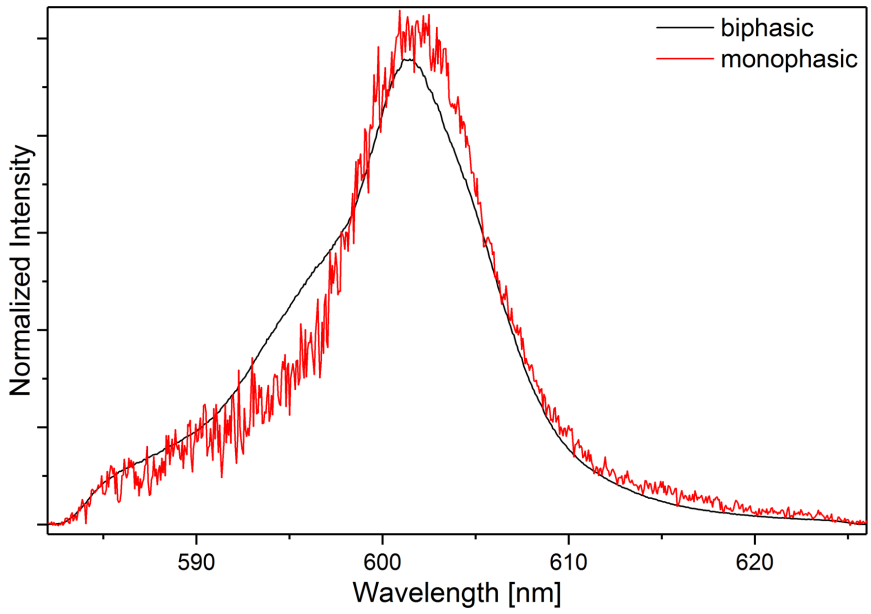

Fig. 8 Comparison of emission spectra of the $\left[\mathrm{Cm}(\mathrm{DMDOHEMA})_{3}\right]^{3+}$ complex (red line) and of species I (black line).

The effect of the nitrate concentration on the organic phase speciation is obvious considering the equilibrium (3) ( $\mathrm{L}=$ DMDOHEMA),

$$
\left[\mathrm{CmL}_{4}\right]^{3+}+\mathrm{NO}_{3}^{-} \leftrightharpoons\left[\mathrm{CmL}_{3}\left(\mathrm{NO}_{3}\right)\right]^{2+}+L(3)
$$

With increasing nitrate concentration, a DMDOHEMA molecule is replaced by a nitrate anion. To understand the effect of the proton concentration on the organic phase speciation, the nitric acid extraction equilibrium (4) has to be considered.

$$
H^{+}+\mathrm{NO}_{3}^{-}+L \leftrightharpoons\left(\mathrm{HNO}_{3}\right) \cdot \mathrm{L}(4)
$$

With increasing proton concentration the DMDOHEMA concentration decreases, shifting equilibrium (3) to the right, i.e. towards species I.

\section{Vibronic side-band spectroscopy}

To support the proposed stoichiometries of the $\mathrm{Cm}(\mathrm{III})$ DMDOHEMA complexes formed during solvent extraction, vibronic side-band spectroscopy (VSBS) is performed on the 1:3 (species I) and 1:4 (species II) complexes. This technique allows the investigation of the vibrations of functional groups coordinated to the probed metal ion. The recorded spectra include the zero phonon line (ZPL) originating from the $\mathrm{Cm}$ (III) ${ }^{6} D^{\prime} 7 / 2 \rightarrow{ }^{8} S^{\prime} 7 / 2$ transition and the side bands. Side bands result from changes in the dipole moment of the ligand field due to internal vibrations upon excitation of the probed metal ion. The energy of a vibration is calculated from the position of the side band relative to the ZPL:

$$
E(\text { vibration })=E(Z P L)-E(\text { vibronic sideband })(5)
$$

Due to the inner-sphere coordination of a nitrate anion in the 1:3 complex, different vibronic side bands should be 
obtained for the 1:3 and 1:4 Cm(III)-DMDOHEMA complexes. To avoid possible superposition of $\mathrm{N}-\mathrm{O}$ stretching and $\mathrm{H}-\mathrm{O}-\mathrm{H}$ bending vibrations, additional samples are prepared by extracting from deuterated aqueous phases.

Figure 9 displays the vibronic side bands of the 1:3 (top) and 1:4 (bottom) complexes extracted from deuterated aqueous phases. The zero phonon lines are located at $\mathrm{ZPL}_{1: 3}$ complex $=$ $601.3 \mathrm{~nm}$ and $Z \mathrm{ZL}_{1: 4 \text { complex }}=604.2 \mathrm{~nm}$. The vibronic side-band spectra of the 1:3 and 1:4 complexes show distinct differences between $900 \mathrm{~cm}^{-1}$ and $1300 \mathrm{~cm}^{-1}$. Bands at $1435 \mathrm{~cm}^{-1}$ with a shoulder at $1590 \mathrm{~cm}^{-1}$ and at $2958 \mathrm{~cm}^{-1}$ are observed in both the $1: 3$ and the $1: 4$ complex. Furthermore, the $1: 3$ complex shows a band at $2380 \mathrm{~cm}^{-1}$ while the $1: 4$ complex displays one at $2224 \mathrm{~cm}^{-1}$.

The bands at $2380 \mathrm{~cm}^{-1}$ (1:4 complex) and $2224 \mathrm{~cm}^{-1}$ (1:3 complex) are assigned to the O-D stretching mode by comparing the vibronic side-band spectra of $\left[\mathrm{CmL}_{3}\left(\mathrm{NO}_{3}\right)\left(\mathrm{H}_{2} \mathrm{O}\right)\right]^{2+}$ with $\left[\mathrm{CmL}_{3}\left(\mathrm{NO}_{3}\right)\left(\mathrm{D}_{2} \mathrm{O}\right)\right]^{2+}$ and $\left[\mathrm{CmL}_{4}\left(\mathrm{H}_{2} \mathrm{O}\right)\right]^{3+}$ with $\left[\mathrm{CmL}_{4}\left(\mathrm{D}_{2} \mathrm{O}\right)\right]^{3+}$ (see supplementary information, Figure $\mathrm{S} 5$ ). Moreover, the O-D stretching mode of the $1: 3$ complex is red-shifted by approximately $160 \mathrm{~cm}^{-1}$ relative to the $1: 4$ complex.
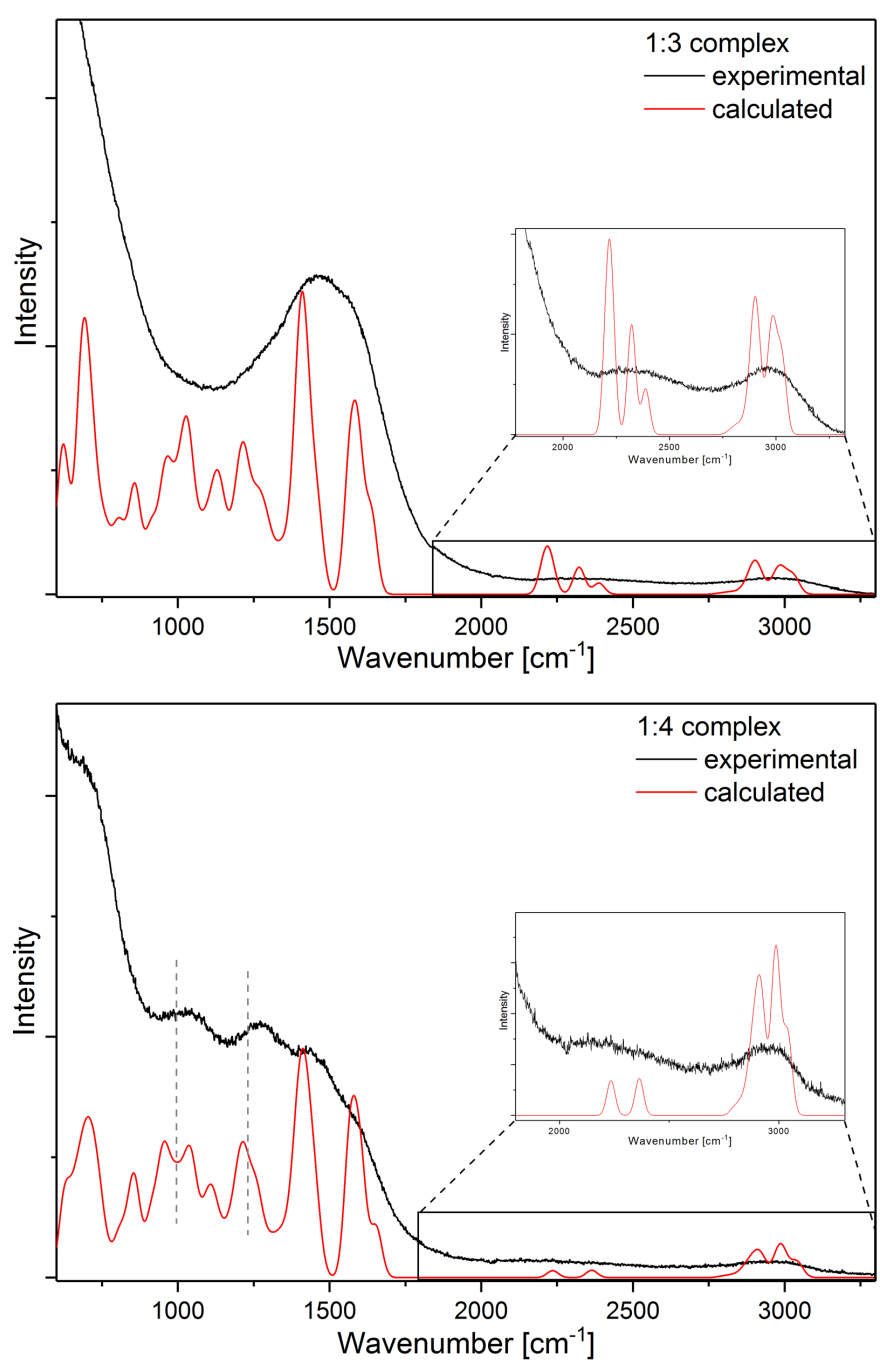

Fig. 9 Comparison of the experimental and calculated VSB spectra of the 1:3 (top) and 1:4 (bottom) Cm(III)-DMDOHEMA complexes extracted from deuterated aqueous solutions. Experimental conditions: $\quad c(C m(I I I))_{\text {ini }}=1 \times 10^{-7} \mathrm{~mol} / \mathrm{L}$; $c($ DMDOHEMA $\left.)=0.4 \mathrm{~mol} / \mathrm{L} ; \mathrm{c}\left(\mathrm{NO}_{3}{ }^{-}\right)_{\text {ini }}=6.0 \mathrm{~mol} / \mathrm{L}\right), \mathrm{c}\left(\mathrm{D}^{+}\right)_{\text {ini }}=6.0 \mathrm{~mol} / \mathrm{L}(1: 3 \mathrm{complex})$ and $10^{-3} \mathrm{~mol} / \mathrm{L}(1: 4$ complex)
To assign the other observerd vibrational modes and to explain similarities and differences in the vibronic side-band spectra, the structures of the proposed 1:3 and 1:4 complexes are optimised and vibrational spectra are calculated using density functional theory (DFT).

\section{Computational results}

The results of the structure optimisation of the 1:3 complex reveal a preferred monodentate coordination of the nitrate anion. In addition, two water molecules bind to $\mathrm{Cm}$ (III), forming hydrogen bonds to the non-coordinating nitrate oxygens (see Figure 10). For the 1:3 complex with a bidentate nitrate no energy minimum is found. Therefore, according to DFT calculations the stoichiometry of the 1:3 complex is $\left[\mathrm{Cm}(\mathrm{DMDOHEMA})_{3}\left(\mathrm{NO}_{3}\right)\left(\mathrm{X}_{2} \mathrm{O}\right)_{2}\right]^{2+}(\mathrm{X}=\mathrm{H}, \mathrm{D})$.

For the 1:4 complex, the DFT results suggest one remaining water molecule in the first coordination shell, which is in excellent agreement with the measured fluorescence lifetimes.

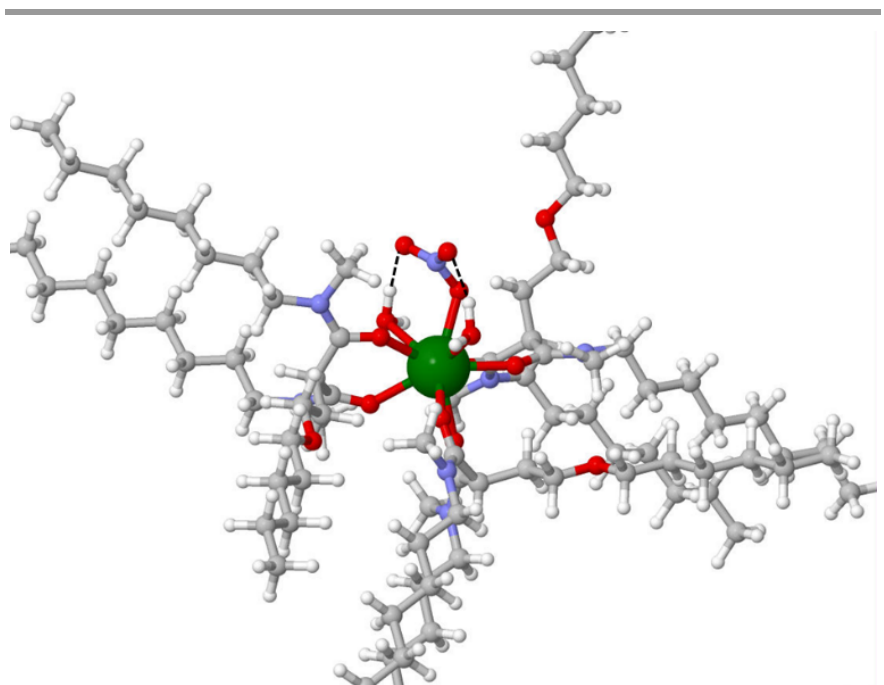

Fig. 10 Calculated structure of the $\left[\mathrm{Cm}(\mathrm{DMDOHEMA})_{3}\left(\mathrm{NO}_{3}\right)\left(\mathrm{H}_{2} \mathrm{O}\right)_{2}\right]^{2+}$ complex. Hydrogen bonds are indicated by dotted lines.

Using the optimised structures of the 1:3 and 1:4 complexes, vibrational spectra are computed and shown in Figure 9. Calculated $D_{2} \mathrm{O}$ vibrations occur in the range of $2217 \mathrm{~cm}^{-1}$ $2388 \mathrm{~cm}^{-1}$. The hydrogen bonding to the coordinated nitrate anion in the 1:3 complex results in a red-shift of the O-D stretching vibration compared to that of the $1: 4$ complex. $\mathrm{D}_{2} \mathrm{O}$ bending or scissoring modes are located around $1103 \mathrm{~cm}^{-1}$ $1143 \mathrm{~cm}^{-1}$. Symmetric and asymmetric carbonyl stretching vibrations are found at $1410 \mathrm{~cm}^{-1}$ and $1582 \mathrm{~cm}^{-1}$ in both complexes. The vibrations in the range of $2906 \mathrm{~cm}^{-1}-$ $3043 \mathrm{~cm}^{-1}$ result from $\mathrm{C}-\mathrm{H}$ stretching. The lower bands in the range of $900 \mathrm{~cm}^{-1}-1300 \mathrm{~cm}^{-1}$ correspond to stretching and twisting modes of the malonamide frame.

These modes are dependent on the steric hindrance of the coordinating ligands, which increases from the 1:3 to the 1:4 complex. In particular, the $\mathrm{C}^{(1)}-\mathrm{C}^{(2)}$ and $\mathrm{C}^{(2)}-\mathrm{C}^{(3)}$ stretching vibrations at $957 \mathrm{~cm}^{-1}, 1040 \mathrm{~cm}^{-1}$ and $1256 \mathrm{~cm}^{-1}$ increase in intensity for the 1:4 complex (see Figure 11 for $\mathrm{C}$ atom assignment). The out-of-plane motion of the $C^{(2)}$ atom is redshifted by $50 \mathrm{~cm}^{-1}$ in the $1: 4$ complex compared to the $1: 3$ complex. 
Two different vibrational modes of the 1:4 complex are shown in In Figure 11. They are more pronounced due to steric hindrance and, therefore, are one of the contributing factors to the differences observed for the 1:3 and 1:4 complex (for clarity only a part of one DMDOHEMA molecule is shown).

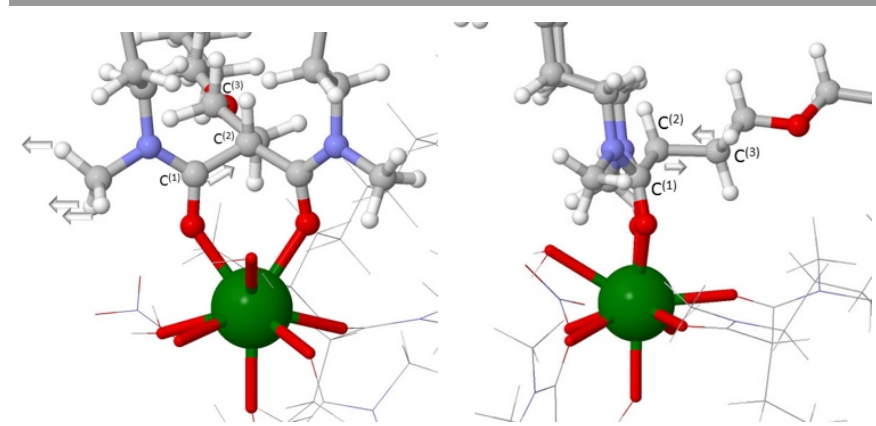

Fig. 10 Visualisation of the vibration modes of the $\left[\mathrm{Cm}(\mathrm{DMDOHEMA})_{4}\left(\mathrm{H}_{2} \mathrm{O}\right)\right]^{3+}$ complex at $957 \mathrm{~cm}^{-1}\left(\right.$ left, $\left.C^{(1)}-C^{(2)}\right)$ and $1040 \mathrm{~cm}^{-1}$ (right, , $\left.C^{(2)}-C^{(3)}\right)$.

Finally, the nitrogen $\mathrm{N}-\mathrm{O}$ stretching vibration is calculated at $1046 \mathrm{~cm}^{-1}$. The energy and the assignment of the peaks in the calculated vibrational spectra are given in Table 1.

Table 1 Assignment of the vibrating functional groups and atoms in the calculated vibrational spectra.

\begin{tabular}{|c|c|c|c|}
\hline \multicolumn{2}{|c|}{$\begin{array}{c}{\left[\mathrm{Cm}(\mathrm{DMDOHEMA})_{3}\left(\mathrm{NO}_{3}\right)\left(\mathrm{D}_{2} \mathrm{O}\right)_{2}\right]^{2+}} \\
(1: 3 \text { complex })\end{array}$} & \multicolumn{2}{|c|}{$\begin{array}{c}{\left[\mathrm{Cm}(\mathrm{DMDOHEMA})_{4}\left(\mathrm{D}_{2} \mathrm{O}\right)\right]^{3+}} \\
(1: 4 \text { complex })\end{array}$} \\
\hline Energy $\left[\mathrm{cm}^{-1}\right]$ & Vibration & Energy $\left[\mathrm{cm}^{-1}\right]$ & Vibration \\
\hline 694 & $\mathrm{~N}-\mathrm{O}$; scissoring & & \\
\hline 853-1024 & $\begin{array}{l}\text { Malonamide } \\
\text { framework }\end{array}$ & $705-1108$ & $\begin{array}{l}\text { Malonamide } \\
\text { framework }\end{array}$ \\
\hline 1127 & O-D scissoring & & \\
\hline 1264 & $\begin{array}{l}C^{(2)}-C^{(3)} \text { dihedral } \\
\text { twisting }\end{array}$ & 1214 & $\begin{array}{l}\mathrm{C}^{(2)}-\mathrm{C}^{(3)} \text { dihedral } \\
\text { twisting }\end{array}$ \\
\hline $1410-1582$ & $\mathrm{C}=\mathrm{O}$ stretching & $1410-1582$ & $\mathrm{C}=\mathrm{O}$ stretching \\
\hline $2217-2388$ & O-D stretching & 2237-2309 & O-D stretching \\
\hline $2906-3021$ & $\mathrm{C}-\mathrm{H}$ stretching & 2907-3043 & $\mathrm{C}-\mathrm{H}$ stretching \\
\hline
\end{tabular}

Comparising the experimental and calculated spectra the energy of the vibrational modes of the $1: 3$ and $1: 4$ complex are in very good agreement. The deviations in the intensities are due to the theoretical approach (Figure 9). Nevertheless, the energies of all observed vibrational modes, including the differences between the 1:3 and 1:4 complex, are very well described by the DFT calculations. The calculations elucidate the coordination mode of the nitrate anion in the 1:3 complex and support the proposed stoichiometries of the $\mathrm{Cm}$ (III)DMDOHEMA complexes.

\section{Conclusions}

The stoichiometry of the complexes formed upon extraction of $\mathrm{Cm}$ (III) from acidic nitrate solutions into DMDOHEMA dissolved in kerosene has been studied using TRLFS, VSBS and DFT.

Monophasic experiments with DMDOHEMA in 1-octanol containing $1.7 \mathrm{~mol} / \mathrm{L}$ water have been performed. The formation of the $\left[\mathrm{Cm}(\text { DMDOHEMA })_{n}\right]^{3+}$ complexes $(n=1-3)$ has been proven and stability constants have been derived: log $\beta_{1}^{\prime}=2.6 \pm 0.3, \log \beta^{\prime}{ }_{2}=4.0 \pm 0.5$ and $\log \beta_{3}^{\prime}=4.3 \pm 0.5$. The stability constants show that DMDOHEMA is a rather weak ligand in comparison to other oxygen based extraction agents. Moreover, the existence of a 1:4 complex has been indicated by fluorescence lifetime measurements.

In liquid-liquid extraction experiments the formation of two different species has been observed in dependence of the proton and nitrate concentrations. The two species have been identified as the $1: 3$ and 1:4 Cm(III)-DMDOHEMA complexes by comparison with the single component spectra of the monophasic experiment. The 1:3 complex is present at high proton and nitrate concentrations while the 1:4 complex is formed at low proton and nitrate concentrations. This is explained by the reduction of the free DMDOHEMA concentration due to the extraction of nitric acid.

To support our proposed stoichiometries VSBS and DFT calculations have been performed. Both the $1: 3$ and 1:4 complexes exhibit characteristic, distinguishable vibronic side bands. Calculated energies of the vibrational modes are in very good agreement with the experimental data, supporting the proposed stoichiometries.

In conclusion, the DMDOHEMA complexes that form when extracting $\mathrm{Cm}$ (III) from acidic nitrate solutions have been determined using a combined approach of TRLFS, VSBS and DFT:

- $\quad\left[\mathrm{Cm}(\mathrm{DMDOHEMA})_{3}\left(\mathrm{NO}_{3}\right)\left(\mathrm{H}_{2} \mathrm{O}\right)_{2}\right]^{2+}$ (prevailing at high proton and nitrate concentrations, hence the free DMDOHEMA concentration is low)

- $\quad\left[\mathrm{Cm}(\mathrm{DMDOHEMA})_{4}\left(\mathrm{H}_{2} \mathrm{O}\right)\right]^{3+}$ (prevailing at low proton and nitrate concentrations, hence the free DMDOHEMA concentration is high).

The solvent extraction equilibrium mode ${ }^{20}$ postulates the extraction of $A m(I I I)$ as $1: 4,1: 3$ and $1: 2$ complexes, with increasing nitric acid concentration (see Table 2). Considering the minute differences in the chemical properties of Am(III) and $\mathrm{Cm}$ (III), the spectroscopic results provide evidence for the 1:3 and 1:4 complexes. No evidence for the existence of a 1:2 complex has been found. The solvent extraction equilibrium model will be revisited, accounting for the findings of this study.

Table 2 Comparision of the stoichiometry of the An(III)-DMDOHEMA complexes determined by a solvent extraction equilibrium mode ${ }^{20}$ and TRLFS ( $L=$ DMDOHEMA).

\begin{tabular}{cccc} 
& SX equilibrium model & TRLFS & \\
\hline $1: 4$ & $A m L_{4}\left(\mathrm{NO}_{3}\right)_{3}$ & {$\left[\mathrm{CmL}_{4}\left(\mathrm{H}_{2} \mathrm{O}\right)\right]^{3+}$} & Low $\left[\mathrm{H}^{+}\right]$and $\left[\mathrm{NO}_{3}{ }^{-}\right]$ \\
$1: 3$ & $\mathrm{AmL}_{3}\left(\mathrm{NO}_{3}\right)_{3}\left(\mathrm{HNO}_{3}\right)$ & {$\left[\mathrm{CmL}_{3}\left(\mathrm{NO}_{3}\right)\left(\mathrm{H}_{2} \mathrm{O}\right)_{2}\right]^{2+}$} & High $\left[\mathrm{H}^{+}\right]$and $\left[\mathrm{NO}_{3}^{-}\right]$ \\
$1: 2$ & $\mathrm{AmL}_{2}\left(\mathrm{NO}_{3}\right)_{3}\left(\mathrm{HNO}_{3}\right)_{2}$ & Not observed &
\end{tabular}

\section{Conflicts of interest}

There are no conflicts to declare.

\section{Acknowledgements}

This work has received funding from the European Research Council (ERC) under the European Union's Horizon 2020 research and innovation programme (project GENIORS, grant agreement $\quad N^{\circ}$ 755171). Rikard Malmbeck, European Commission, DG JRC, is acknowledged for providing DMDOHEMA. This paper was presented at the $18^{\text {th }}$ Radiochemical Conference (RadChem 2018) held in Mariánské Lázně, Czech Republic, 13-18 May 2018. 


\section{Notes and references}

1. T. H. Siddall, R. L. McDonald and W. E. Stewart, J. Mol. Spectrosc., 1968, 28, 243-264.

2. B. K. McNamara, G. J. Lumetta and B. M. Rapko, Solvent Extr Ion Exc, 1999, 17, 1403-1421.

3. L. Spjuth, J. O. Liljenzin, M. Skålberg, M. J. Hudson, G. Y. S. Chan, M. G. B. Drew, M. Feaviour, P. B. Iveson and C. Madic, Radiochim Acta, 1997, 78, 39-46.

4. G. Y. S. Chan, M. G. B. Drew, M. J. Hudson, P. B. Iveson, J.O. Liljenzin, M. Skalberg, L. Spjuth and C. Madic, J. Chem. Soc. Dalton Trans., 1997, 4, 649-660.

5. C. Musikas and H. Hubert, Solvent Extr. Ion Exch., 1987, 5, 877-893.

6. C. Madic and M. J. Hudson, High-level liquid waste partitioning by means of completely incinerable extractants, EUR 18038, European Commission, Luxembourg, 1998.

7. C. Musikas, Separ. Sci. Technol., 1988, 23, 1211-1226.

8. G. M. Casparini and G. Grossi, Separ Sci Technol, 1980, 15, 825-844.

9. B. N. Laskorin, V. V. Yakin, E. A. Fillipov, G. M. Chumokova, V. A. Belof and G. G. Arkipova, Sov. Radiochem., 1978, 20, 511-515.

10. L. Berthon, J. M. Morel, N. Zorz, C. Nicol, H. Virelizier and C. Madic, Separ Sci Technol, 2001, 36, 709-728.

11. P. B. Iveson, M. G. B. Drew, M. J. Hudson and C. Madic, Dalton Transactions, 1999, 20, 3605-3610.

12. C. Madic, F. Testard, M. J. Hudson, J.-O. Liljenzin, B. Christiansen, M. Ferrando, A. Facchini, A. Geist, G. Modolo, A. G. Espartero and J. De Mendoza, PARTNEW-New Solvent Extraction Processes for Minor Actinides. Final Report; CEA-R-6066, Commissariat à l'Énergie Atomique, France, 2004.

13. D. Serrano-Purroy, P. Baron, B. Christiansen, R. Malmbeck, C. Sorel and J. P. Glatz, Radiochim Acta, 2005, 93, 351-355.

14. C. Rostaing, C. Poinssot, D. Warin, P. Baron and B. Lorrain, Procedia Chemistry, 2012, 7, 367-373.

15. M. Miguirditchian, H. Roussel, L. Chareyre, P. Baron, D. Espinoux, J.-N. Calor, C. Viallesoubranne, B. Lorrain and M. Masson, Proc. Internat. Conf. GLOBAL 2009 (The Nuclear Fuel Cycle: Sustainable Opions and Industrial Perspectives), Paris, France, 6-11 September, 2009.

16. M. Carrott, A. Geist, X. Heres, S. Lange, R. Malmbeck, M. Miguirditchian, G. Modolo, A. Wilden and R. Taylor, Hydrometallurgy, 2015, 152, 139-148.

17. C. Musikas and H. Hubert, Solvent Extr. Ion Exch., 1987, 5, 151-174.

18. L. Nigond, C. Musikas and C. Cuillerdier, Solvent Extr. Ion Exch., 1994, 12, 261-296.

19. L. Spjuth, J. O. Liljenzin, M. J. Hudson, M. G. B. Drew, P. B. Iveson and C. Madic, Solvent Extr Ion Exc, 2000, 18, 1-23.

20. A. Geist, presented in part at the Proc. Internat. Conf. ATALANTE 2008 (Nuclear Fuel Cycles for a Sustainable Future), Montpellier, France, 19-23 May, 2008.

21. N. M. Edelstein, R. Klenze, T. Fanghänel and S. Hubert, Coordin Chem Rev, 2006, 250, 948-973.

22. R. Klenze, J. Kim and H. Wimmer, Radiochim Acta, 1991, 52, 97-104.

23. M. Trumm, C. Wagner, B. Schimmelpfennig, A. Geist and P. J. Panak, Dalton Transactions, 2016, 45, 12308-12311.

24. S. L. Chodos and R. A. Satten, The Journal of Chemical Physics, 1975, 62, 2411-2417.
25. H. Ewald, Annalen der Physik, 1939, 426, 209-236.

26. S. Freed, Reviews of Modern Physics, 1942, 14, 105-111.

27. I. E. Iben, M. Stavola, R. B. Macgregor, X. Y. Zhang and J. M. Friedman, Biophysical Journal, 1991, 59, 1040-1049.

28. J. Wiedenmann, S. Ivanchenko, F. Oswald, F. Schmitt, C. Röcker, A. Salih, K.-D. Spindler and G. U. Nienhaus, Proceedings of the National Academy of Sciences of the United States of America, 2004, 101, 15905-15910.

29. B. E. Lang, J Chem Eng Data, 2012, 57, 2221-2226.

30. T. H. Vu, PH.D., Universite Louis Pasteur a Strasbourg, 2008.

31. A. D. Becke, Physical Review A, 1988, 38, 3098-3100.

32. J. P. Perdew, Physical Review B, 1986, 33, 8822-8824.

33. F. Weigend and R. Ahlrichs, Physical Chemistry Chemical Physics, 2005, 7, 3297-3305.

34. W. Küchle, M. Dolg, H. Stoll and H. Preuss, The Journal of Chemical Physics, 1994, 100, 7535-7542.

35. TURBOMOLE V7.0, a development of University of Karlsruhe and Forschungszentrum KarlsruheGmbH, 19892007, TURBOMOLE GmbH, since 2007. http://www.turbomole.com

36. P. Lindqvist-Reis, R. Klenze, G. Schubert and T. Fanghanel, J Phys Chem B, 2005, 109, 3077-3083.

37. T. Kimura, G. R. Choppin, Y. Kato and Z. Yoshida, Radiochim Acta, 1996, 72, 61-64.

38. W. T. Carnall and K. Rajnak, The Journal of Chemical Physics, 1975, 63, 3510-3514.

39. S. Trumm, G. Lieser and P. J. Panak, Radiochim. Acta, 2011, 99, 783.

40. A. Bremer, U. Mullich, A. Geist and P. J. Panak, New J Chem, 2015, 39, 1330-1338.

41. A. Wilden, G. Modolo, S. Lange, F. Sadowski, B. B. Beele, A. Skerencak-Frech, P. J. Panak, M. Iqbal, W. Verboom, A. Geist and D. Bosbach, Solvent Extr. Ion Exch., 2014, 32, 119-137. 